Canadian

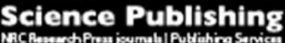

Biochemistry and Cell Biology

Biochimie et biologie cellulaire

\title{
Characterization of $2,3,6,7,10,11$-hexahydroxytriphenylene and its effects on cell viability in human cancer cell lines
}

\begin{tabular}{|r|l|}
\hline Journal: & Biochemistry and Cell Biology \\
\hline Manuscript ID & bcb-2015-0093.R2 \\
\hline Manuscript Type: & Article \\
\hline Date Submitted by the Author: & 05-Jan-2016 \\
\hline Complete List of Authors: & $\begin{array}{l}\text { Naidek, Karine; UFPR, Chemistry } \\
\text { Zuconelli, Cristiane; UFPR, Biochemistry } \\
\text { Cruz, Otavio; UFPR, Biochemistry } \\
\text { Ribeiro, Ronny; UFPR, Chemistry } \\
\text { Winnischofer, Sheila; UFPR, Biochemistry } \\
\text { Winnischofer, Herbert; Universidade Federal do Parana, Chemistry }\end{array}$ \\
\hline Keyword: & semiquinone, hexahydroxytriphenylene, cytotoxicity, cell viability \\
\hline &
\end{tabular}

SCHOLARONE ${ }^{m}$

Manuscripts 
Characterization of 2,3,6,7,10,11-hexahydroxytriphenylene and its effects on cell viability in human cancer cell lines

Karine P. Naidek ${ }^{\mathrm{a} \#}$, Cristiane R. Zuconelli ${ }^{\mathrm{b} \#}$, Otavio M. Cruz ${ }^{\mathrm{b}}$, Ronny Ribeiro ${ }^{\mathrm{a}}$, Sheila M.B. Winnischofer ${ }^{\mathrm{b}}$ and Herbert Winnischofer ${ }^{\mathrm{a}^{*}}$

aUniversidade Federal do Paraná, Dep. Química, C.P. 19081, 81531-980, Curitiba, Paraná, Brazil,

${ }^{\mathrm{b}}$ Universidade Federal do Paraná, Dep. Bioquímica e Biologia Molecular, C.P. 19046, 81531-980, Curitiba, Paraná, Brazil.

\# Both authors contributed equally to this paper

* Corresponding author.

Correspondence should be addressed to Herbert Winnischofer

Universidade Federal do Paraná, Departamento de Química. Av. Cel. Francisco H. dos Santos, 210 - Jardim das Américas, Curitiba, Paraná, Brazil. 81.531-980, CP 19081;

E-mail hwin@ufpr.br, Tel.+55-41-3361-3181, Fax.+55-41-3361-3186 


\begin{abstract}
We synthesized 2,3,6,7,10,11-hexahydroxytriphenylene (HHTP); characterized it by electrochemistry, spectroelectrochemistry and EPR techniques; and evaluated its cytotoxicity to human cancer cell lines. The results revealed that HHTP has accessible higher-oxidation states, especially the tris-semiquinone monoradical. This species is stable and is formed after being stored for months. HHTP exhibited cytotoxic effects on five human cancer cell lines, including glioma and lung cancer cells. The cytotoxic effect was evaluated based on the decrease in cell viability, increases in the percentage of cells with fragmented DNA, and elevated numbers of Annexin V/PI-positive cells after HHTP treatment.
\end{abstract}

Keywords: semiquinone, hexahydroxytriphenylene, cytotoxicity, cell viability 


\section{Introduction}

The molecule 2,3,6,7,10,11-hexahydroxytriphenylene (HHTP) has a planar and fully conjugated tris-catechol structure. It differs from catechol and ordinary polyphenols because of the fused aromatic rings that stabilize excited species, and in its greater hydrophobicity. Catechol is an important molecule, with many applications and significant toxic effects on living organisms.(Schweigert et al. 2001) Catechols are intermediaries in the degradation of aromatic compounds, and although they are omnipresent in nature, they are toxic to some organisms. The mode of action of catechols in cells is not fully understood, but two main properties are involved(Schweigert et al. 2001): the capacity to bind to metal ions, forming stable complexes; and the ability to oxidize, forming the semiquinone radical and $o$-benzoquinone. Both properties are responsible for causing irreparable damage to DNA, protein and membranes.(Schweigert et al. 2001)

The conjugated electron structure of the planar HHTP also confers interesting electrochemical and spectroscopic properties, which have been little investigated. Ward and co-workers (Barthram et al. 1998; Barthram et al. 2000; Grange et al. 2010) investigated inorganic complexes of HHTP with ruthenium and osmium, and their electrochemical and spectroscopic properties. The trinuclear ruthenium complex is stable in the trissemiquinone oxidation state, and can exhibit up to six redox processes. A rutheniumcomplex film on a conductive glass substrate switched between redox states, and has been proposed as a "smart window".(Grange et al. 2010) 
Research involving HHTP has increased tremendously, especially in the last two years (Xiang et al. 2010; Yuan et al. 2012; Guo et al. 2013; Adamson et al. 2014; Giovanelli et al. 2014; Liu et al. 2014; Medina et al. 2014); most studies have explored the ability of HHTP to form highly ordered architectures. Hmadeh et al.(Hmadeh et al. 2012) exploited the coordination properties of HHTP to form extended structures with Co(II) and $\mathrm{Ni}(\mathrm{II})$, creating porous crystals.

The planar and conjugated structure of triphenylene allows the formation of $\pi-\pi$ stacks where molecules assemble as columns, resulting in columnar mesophases. Because of the $\pi-\pi$ stacking characteristics, HHTP derivatives have also been intensively investigated as self-assembled thin films, especially in Langmuir-Blodgett films (Karthaus et al. 1992; Tsukruk et al. 1993; Henderson et al. 1997; Vaes et al. 1998) and liquid crystal phases (Beattie et al. 1992; Manickam et al. 2001; Kumar 2004). The columnar stacking properties of triphenylenes were exploited by Ogoshi et al. (Ogoshi et al. 2009) to generate star-shaped and tadpole-shaped structures, which were used as templates for synthesis of wire-assembled gold nanostructures. Côté et al. (Côté et al. 2005) exploited the reactivity of the peripheral groups of a triphenylene derivative, reacting HHTP with diboronic acid to obtain covalent organic frameworks (COF).

Kocyigit et al. (Kocyigit et al. 2010) used HHTP to prepare a Schiff base complexed with metal ions, and suggested that the resulting compounds are highly toxic, but did not mention the possible intrinsic toxicity related to the polyphenol group and polyaromatic nature of HHTP. In the present study, we evaluated the cytotoxicity of free HHTP by determining its effect on cell viability in five human tumor cell lines. Some experiments were compared to its precursor 2,3,6,7,10,11-hexamethoxytriphenylene 
(HMTP) to clarify the contribution of the fused aromatic ring in the absence of the phenol group. For better understanding of the chemical and redox properties that could be involved in the cytotoxic effects of HHTP, the results of electrochemistry, UV-vis spectroelectrochemistry, and EPR analyses are shown.

\section{Materials and methods}

All the reagents and solvents were of analytical grade. Anhydrous $\mathrm{FeCl}_{3}$ was obtained as described in the literature (Manickam et al. 2001). 1,2-Dimethoxybenzene (Veratrol) and $\mathrm{BBr}_{3}$ were purchased from Aldrich and used as received. The solvents were purchased from commercial sources (Sigma-Aldrich and Vetec) and used as received.

\subsection{Synthesis}

Precursor 2,3,6,7,10,11-hexamethoxytriphenylene (HMTP): In a 500-mL round-bottom flask, $231 \mathrm{mmol}(37.5 \mathrm{~g})$ anhydrous $\mathrm{FeCl}_{3}$ was dissolved in $188 \mathrm{~mL}$ dichloromethane and 6 $\mathrm{mL}$ trifluoracetic acid. Under stirring, $90 \mathrm{mmol}$ (12.5 g) veratrol (1,2-dimethoxybenzene) dissolved in $63 \mathrm{~mL}$ dichloromethane was slowly added dropwise. The mixture was stirred for $24 \mathrm{~h}$. The resulting deep-blue solid was separated by filtration, washed with dichloromethane, and dried in a desiccator under vacuum over calcium chloride. The isolated solid was suspended in $65 \mathrm{~mL}$ methanol and stirred for $10 \mathrm{~min}$ while gas emerged and the color of the solid changed to green. The solid was filtered and washed with methanol and water. Then, the solid was dissolved in $65 \mathrm{~mL}$ dichloromethane, and $2.5 \mathrm{~g}$ 
silica was added to the mixture, which was heated and refluxed for $1 \mathrm{~h}$. The suspension was filtered and dried in a desiccator over calcium chloride, and kept in the dark for 4 days. After that, the HMTP was extracted in a soxhlet with $125 \mathrm{~mL}$ dichloromethane for $24 \mathrm{~h}$. The dichloromethane solution was rotoevaporated to dryness, and the solid was suspended in $20 \mathrm{~mL}$ methanol and kept in a freezer $\left(-16^{\circ} \mathrm{C}\right)$ for 4 days. Finally, the crystalline solid was filtered and dried in a desiccator over calcium chloride. This procedure furnished 751 mg of the product (6.1\%). ${ }^{1} \mathrm{H}-\mathrm{NMR}:\left(200 \mathrm{MHz}, 30{ }^{\circ} \mathrm{C}, \mathrm{CDCl}_{3}, \mathrm{TMS}\right) \delta(\mathrm{ppm}): 4.11(18 \mathrm{H})$ and $7.70(6 \mathrm{H})$. IR $v_{\max }\left(\mathrm{cm}^{-1}\right): 2985,2935,2825,1620,1519,1463,1417,1263,1207$, $1157,1047,833,777,624,538$.

2,3,6,7,10,11-hexahydroxytriphenylene (HHTP): $1.47 \mathrm{mmol}(600 \mathrm{mg})$ of 2,3,6,7,10,11-hexamethoxytriphenylene was suspended in $30 \mathrm{~mL}$ dichloromethane maintained at $-80{ }^{\circ} \mathrm{C}$ under continuous stirring. Then, $0.01 \mathrm{~mol}(2.57 \mathrm{~g})$ of $\mathrm{BBr}_{3}$ dissolved in $24 \mathrm{~mL}$ anhydrous dichloromethane was slowly added dropwise. This mixture was stirred overnight while the temperature naturally rose to room temperature. After that, $10 \mathrm{~mL}$ water was added to the mixture and the dichloromethane was removed by rotoevaporation. The solid formed in this process was filtered and recrystallized in water. This procedure furnished $225 \mathrm{mg}$ of the product (47\%). ${ }^{1} \mathrm{H}-\mathrm{NMR}$ : $\left(200 \mathrm{MHz}, 30{ }^{\circ} \mathrm{C}\right.$, DMSO-d 6 , TMS) $\delta$ (ppm): $7.63(0.99 \mathrm{H})$ and $9.35(1.00 \mathrm{H}) . \mathrm{IR} v_{\max }\left(\mathrm{cm}^{-1}\right): 3300,1616,1541,1508,1456$, 1242, 1180, 854 and 578. MS m/z: $323.18\left(\mathrm{M}^{-}\left[\mathrm{C}_{18} \mathrm{H}_{11} \mathrm{O}_{6}\right]^{-}\right) ; 646.98\left(\mathrm{M}_{2}^{-}\left[\mathrm{C}_{36} \mathrm{H}_{23} \mathrm{O}_{12}\right]^{-}\right)$; $970.73\left(\mathrm{M}_{3}^{-}\left[\mathrm{C}_{54} \mathrm{H}_{35} \mathrm{O}_{18}\right]^{-}\right) . \mathrm{CHN}: \mathrm{C}_{18} \mathrm{H}_{12} \mathrm{O}_{6} \cdot \mathrm{H}_{2} \mathrm{O}$ experimental (calculated): \%C: 62.74 (63.16), \%H: $4.03(4.12)$, and \%N: $0.55(0.0)$. 


\subsection{Apparatus and measurements}

UV-vis spectra were obtained from dimethylformamide (DMF) solutions placed in quartz cuvettes, using a Shimadzu UV 2450 spectrometer in the transmission mode in the range of 190 to $1100 \mathrm{~nm}$. The Bruker Vertex 70 spectrophotometer was used to acquire FTIR spectra in the range of 4000 to $400 \mathrm{~cm}^{-1}$. Spectra of the compounds embedded in $\mathrm{KBr}$ pellets were acquired in the transmission mode. The electrochemical experiments were performed on an Ivium Compactstat potentiostat/galvanostat in a three-electrode cell; the $\mathrm{Ag} / \mathrm{Ag}^{+}\left(0.01 \mathrm{~mol} \mathrm{~L}^{-1}\right.$ in $\left.\mathrm{CH}_{3} \mathrm{CN}\right)$ reference electrode was used for experiments conducted with 0.1 mol $\mathrm{L}^{-1} \mathrm{TBAClO}_{4}$ electrolyte solution in DMF. Squarewave voltammetry experiments were conducted with the following parameters: potential step $=0.5 \mathrm{mV}$, amplitude $=40 \mathrm{mV}$, and frequency 40 or $80 \mathrm{~Hz}$. UV-vis spectroelectrochemistry experiments were conducted using the Ivium Compactstat potentiostat/galvanostat coupled with the Agilent 8453 spectrophotometer, and an ALS SEC-C Thin Layer Quartz Glass Spectroelectrochemical cell kit with a Pt gauze working electrode. EPR spectra were obtained from solid samples in a Bruker E500 Spectrometer in the x-band region $(9.5 \mathrm{GHz})$ at room temperature and at $77 \mathrm{~K}$. For EPR experiments, HHTP was analyzed in three forms: freshly prepared, aged for more than 8 months, and an oxidized sample. The oxidized sample of HHTP was generated by the reaction of HHTP with a stoichiometric amount (1:1) of $\mathrm{H}_{2} \mathrm{O}_{2}$ (30\% solution). After stirring for $5 \mathrm{~min}$, the solid was filtered and dried under vacuum. The Thermo Fisher Scientific Inc. LTQ XL Linear Ion Trap Mass Spectrometer was used to record the ESI mass spectra of the compounds at a concentration of $10^{-2} \mathrm{mg} \mathrm{mL}^{-1}$ in dichloromethane. The Bruker DPX 200 spectrometer operating at 4.7 Tesla was used to acquire the ${ }^{1} \mathrm{H}-\mathrm{NMR}(200.13 \mathrm{MHz})$ spectra of the compounds in $\mathrm{CDCl}_{3}$ and DMSO- $\mathrm{d}_{6}$; the signals were assigned to the TMS reference at $303 \mathrm{~K}$. 


\subsection{Cell culture conditions}

We used freshly prepared HHTP samples in all biological-activity experiments. The different tumor cell lines were kindly provided by Prof. Mari C. Sogayar of the Chemistry Institute, University of São Paulo, Brazil. These cells were cultured in DMEM medium (Sigma-Aldrich) supplemented with 10\% fetal bovine serum (FBS, Gibco) and $50 \mu \mathrm{g} \mathrm{mL} \mathrm{m}^{-1}$ gentamicin (Sigma-Aldrich). The cells were maintained at $37{ }^{\circ} \mathrm{C}$ in a $5 \% \mathrm{CO}_{2}$ atmosphere. The HHTP or HMTP compounds were dissolved in DMSO, and cisplatin (cisDDP) was dissolved in $0.9 \% \mathrm{NaCl}$ solution. For cell treatments, all compounds were further diluted in DMEM medium at 5.0, 10 and $25 \mu \mathrm{mol} \mathrm{L}^{-1}$. Cultures were incubated for $48 \mathrm{~h}$. Control conditions consisted of cells maintained in culture medium plus each vehicle (equivalent to $10 \mu \mathrm{mol} \mathrm{L}{ }^{-1}$ treatment).

\subsection{Cell viability analysis}

Cell viability was evaluated through the crystal violet staining assay, as described by Kueng et al. (Kueng et al. 1989). Briefly, cells were seeded in 96-well culture plates and incubated for adhesion during $24 \mathrm{~h}$. Then, the normal medium was replaced by medium containing the above-mentioned concentrations of HHTP, HMTP or cisplatin, and incubated for $48 \mathrm{~h}$. After treatment, the medium was removed, and the cells were washed with phosphate saline buffer (PBS) solution and fixed with 100\% methanol during $10 \mathrm{~min}$. The cells were immersed in a solution of $0.2 \%$ crystal violet in $2 \%$ ethanol for $3 \mathrm{~min}$, and then washed with PBS until the excess crystal violet was cleared. Then, an elution step was performed with $0.05 \mathrm{~mol} \mathrm{~L}^{-1}$ sodium citrate diluted in 50\% ethanol, during $10 \mathrm{~min}$. The absorbance was determined in a microplate reader (Infinite 200, Tecan Group) at $540 \mathrm{~nm}$. The results were expressed as a percentage of viable cells compared to the control (100\%). 


\subsection{Determination of hypodiploid DNA content}

DNA fragmentation was evaluated through the SubG1 analysis using propidium iodide, as described by Riccardi and Nicoletti (Riccardi and Nicoletti 2006). Human glioma cells (4 x $10^{4}$ cells/plate) were incubated in 12 -well plates $\left(24 \mathrm{~h}, 37^{\circ} \mathrm{C}\right)$. The cells were then treated with $10 \mu \mathrm{mol} \mathrm{L}{ }^{-1}$ of HHTP or HMTP for $48 \mathrm{~h}$. After centrifugation, the pellet was washed twice with PBSA and incubated with a cold staining solution of $50 \mu \mathrm{g} \cdot \mathrm{mL}^{-1}$ propidium iodide, $0.1 \%$ Triton $\mathrm{X}-100,0.1 \%$ sodium citrate, and $0.2 \mathrm{mg} \mathrm{mL}^{-1}$ RNAse A (30 min, in the dark). The samples were run in a FACSCalibur System, and the DNA histograms obtained were analyzed to measure the proportion of sub-G1 hypodiploid cells, using WinMDI 2.9 software (developed by Joseph Trotter).

\subsection{Apoptosis assay}

Apoptosis was determined in human glioma cells using the Annexin V-FITC and PI staining. Cells were seeded onto 12-well plates and treated with HHTP $(10 \mu \mathrm{M})$ or equal volume of DMSO (vehicle-control group) for $48 \mathrm{~h}$. Both floating and adherent cells were collected. After centrifugation, the pellet was resuspended in $100 \mu \mathrm{L}$ of binding buffer, and stained with $5 \mu \mathrm{L}$ of Annexin V-FITC and $5 \mu \mathrm{L}$ of PI for $15 \mathrm{~min}$ at $25^{\circ} \mathrm{C}$ in the dark. Samples were diluted in $400 \mu \mathrm{L}$ of binding buffer and analyzed by flow cytometry. For each measurement, at least 10,000 cells were acquired using an Accuri $\mathrm{C}^{\circledR}{ }^{\circledR}$ cytometer (BD).

3 Results and discussion 
The ${ }^{1} \mathrm{H}-\mathrm{NMR}$ spectra of the precursor HMTP and the HHTP were clean, exhibiting two signals corresponding to the arylic and methylic/hydroxylic hydrogens of the products (Figs. SI01, SI02). The HHTP spectra also showed a water-hydrogen signal that, in addition to the FTIR spectrum and CHN result, suggest the presence of water in the sample. The ESI-MS spectrum (Fig. SI03) showed a more intense peak at $(\mathrm{m} / \mathrm{z}) 323$, which corresponds to the deprotonated molecular ion with the formula $\left[\mathrm{C}_{18} \mathrm{H}_{11} \mathrm{O}_{6}\right]^{-}$, in addition to peaks at 647 and 971. Isolation of the peak at 647 and $20 \mathrm{~V}$ cone voltage generated the peak at $\mathrm{m} / \mathrm{z}=$ 323 (Fig. SI04). The peaks at 647 and 971 were attributed to the presence of dimers and trimers, respectively, of HHTP, revealing the tendency of HHTP to aggregate in the gaseous phase due to $\pi-\pi$ stacking.

Since catechols have the ability to oxidize, forming the semiquinone radical and $o$ benzoquinone, which cause irreparable damage and lead to cytotoxic effects, we characterized HHTP by electrochemistry, spectroelectrochemistry, and EPR to elucidate its redox properties. The cyclic voltammetry (CV) of HHTP in DMF (Fig. 1A), starting in the positive potential direction, showed three very intense anodic peaks over $0.1 \mathrm{~V}(0.6$ vs SHE); a cathodic peak at $-0.8 \mathrm{~V}$, characteristic of an irreversibly adsorbed species; and other low-intensity current peaks. The squarewave voltammetry (SWV) showed the same intense current peaks (Fig. 1B). The $-0.8 \mathrm{~V}$ cathodic peak was three times more intense than each of the anodic peaks over $0.1 \mathrm{~V}$, indicating that the reduction related to the three-step oxidation occurred in a single step in an adsorbed species. The low-intensity current peaks are probably associated with species generated in chemically-electrochemically coupled reactions in the presence of water in the electrolyte solution. The cathodic peak behavior of an adsorbed species is very similar to the description by Barthram et al. (Barthram et al. 
1998). Therefore, the three oxidation processes were attributed to HHTP processes: 1. $\mathrm{CatCatCat} \rightarrow \mathrm{CatCatSq}$; 2. CatCatSq $\rightarrow \mathrm{CatSqSq}$; and 3. CatSqSq $\rightarrow \mathrm{SqSqSq}$; (where Cat. $=$ catechol and $\mathrm{Sq}=$ semiquinone forms of three residues present in HHTP). In the reduction direction, we postulated the single 3-electron process, SqSqSq $\rightarrow$ CatCatCat.

Although in the CV experiment we could distinguish three oxidation steps, using UV-vis spectroelectrochemistry we observed a single process, which decreased the $\pi-\pi^{*}$ bands below $300 \mathrm{~nm}$ and formed a broad band in the $400-500 \mathrm{~nm}$ region (Fig. 1C). Because these three oxidation processes are irreversible, chemically-electrochemically coupled reactions occur at the time scale of the measurement. In the experiments, we applied a fixed potential of $1.0 \mathrm{~V}$ and the spectra were recorded in sequence, with 1-s intervals. The result indicated that only a single equilibrium occurred, revealed by the isosbestic point at $339 \mathrm{~nm}$ (Fig. 1C). We assume that the process observed in the spectroelectrochemical experiment is CatCatCat $\rightarrow$ SqSqSq. According to Grange et al. (Grange et al. 2010) the tris-semiquinone SqSqSq form of HHTP is a monoradical. Considering this, the broad band observed in the $400-500 \mathrm{~nm}$ region is associated with the radical transition.

The freshly prepared HHTP exhibited no signal in the EPR spectrum. The HHTP treated with 1 equivalent stoichiometric amount of hydrogen peroxide led to an EPR active species, which exhibited a signal with $\mathrm{g}=2.00402$, which at room temperature had a peakto-peak width $=0.56 \mathrm{mT}$ (Fig. SI05), characteristic of an organic free radical. With the hydrogen peroxide added in a 1:1 ratio, HHTP would lead to the CatCatSq form, but considering the spectroelectrochemical result and the oxidation processes occurring at closely similar potential values, we assume that the SqSqSq monoradical was also detected 
in the EPR experiment, contributing to the signal observed. The formation of a radical is not exclusive to the catechol residue of HHTP. The methoxylated HMTP also exhibited an EPR signal (Fig. SI06) with $\mathrm{g}=2.00426$ and peak-to-peak width $=0.57 \mathrm{mT}$ at room temperature after treatment with hydrogen peroxide. This shows that the aromatic fused ring stabilizes the oxidized form as a radical and contributes to HHTP reactivity. A very similar EPR signal was obtained by aging the HHTP for months, as dried samples in vials. The aged HHTP also showed a very intense and narrower signal with $\mathrm{g}=2.00234$ and a peak-to-peak width $=0.4 \mathrm{mT}$ (Fig. 1D), which was attributed to the SqSqSq monoradical form of HHTP. As the HHTP is easily converted to the semiquinone form and a radical is highly reactive with biomolecules, the cytotoxicity of HHTP based on its effects on cell viability in human cancer cell lines was investigated.

In order to assess the effects of HHTP on cell viability, we evaluated the effects of HHTP treatment on five human cell lines, including glioma and lung-cancer cells. The cells were exposed to different concentrations of HHTP $\left(5-25 \mu \mathrm{mol} \mathrm{L}^{-1}\right)$, and then the cellular viability was determined by crystal violet staining. After treatment for $48 \mathrm{~h}$, a significant decrease in the number of viable cells was observed in all tumor cell lines, compared to the controls (Fig. 2A), reaching more than 35\% reduction in A549 and U87MG cells, and around $20-27 \%$ reduction in A172, T98G and $\mathrm{NCl}-\mathrm{H} 23$ cells with the lowest concentration of HHTP $\left(5 \mu \mathrm{mol} \mathrm{L} \mathrm{L}^{-1}\right)$. The effects of HHTP at the highest concentration evaluated (25 $\mu \mathrm{mol} \mathrm{L} \mathrm{L}^{-1}$ ) followed the same profile, reaching more than $58 \%$ reduction in A549 and U87MG cells, and around 36-47\% reduction in A172, T98G and NCl-H23 cells. Similar results were obtained with a manual cell-counting method (Fig. SI06). 
All tumor cell lines used in this study grow as adherent cultures, and their usual morphology is polygonal, slightly elongated and sometimes with cytoplasmic filaments. Figure 2B shows the morphological effects of HHTP on U87MG cells; these effects were similar for all tumor cells analyzed. Morphological changes were clearly observed after 48 h of HHTP treatment, since DMSO alone has no effect (Fig. 2B, panel A). The number of cells was clearly reduced and some changes in the cell volume were observed, with cells appearing more flattened (Fig. 2B, panel $\mathrm{C}$ and Fig. 2B, panel D). These data were consistent with the results for cell viability.

The cellular cytotoxicity of HHTP was also compared to a standard chemotherapy drug, cisplatin. Cisplatin (cisDDP) is widely used in the treatment of a variety of human malignancies, and has been tested in combination with temozolomide in patients with recurrent glioblastoma.(Brandes et al. 2004; Silvani et al. 2004) Also, some studies have shown that the use of cisplatin can benefit patients with temozolomide-refractory highgrade malignant glioma.(Zustovich et al. 2009) The human glioma cell lines (U87MG, T98G and A172) were treated separately with HHTP and cisplatin at concentrations ranging from 5 to $25 \mu \mathrm{mol} \mathrm{L} \mathrm{L}^{-1}$ for $48 \mathrm{~h}$. As shown in Figure 3, the in vitro cytotoxicity of HHTP was very similar to that observed for cisplatin at all drug concentrations evaluated.

In addition, we evaluated the proportion of sub-G1 hypodiploid cells, using a flow cytometry analysis. This method can detect cells that have lost some of their DNA in the late stage of apoptosis, following endonuclease activity. Using the nucleic-acid stain propidium iodide (PI), the number of hypodiploid cells undergoing this process can be counted in the sub-G1 region of the PI histogram. The cells were treated with $10 \mu \mathrm{mol} \mathrm{L}-1$ of HHTP for $48 \mathrm{~h}$. As shown in Figure 4, the proportion of sub-G1 hypodiploid cells after 
HHTP treatment increased, from $2.6 \%$ (control conditions) to approximately $10.8 \%$, in both tumor cell lines.

It is well known that one of the earlier events of apoptosis includes the loss of membrane phospholipid asymmetry, with translocation of membrane phosphatidylserine (PS) from the inner side of the plasma membrane to the cell surface. It has been established that PS externalization is regulated by activation of scramblases coupled with inactivation of flippases, through caspase-dependent apoptotic pathways (Balasubramanian et al. 2007; Leventis and Grinstein 2010; Suzuki et al. 2013; Segawa et al. 2014). The presence of PS on the plasma membrane promotes the phagocytic recognition, engulfment and destruction of apoptotic cells (de Cathelineau and Henson 2003; Segawa and Nagata 2015). Therefore, we performed double-staining assays in glioma cell lines using Annexin-V (which has a high affinity for PS) and PI (which stains only membrane-damaged cells). Our results showed that treatment with HHTP significantly reduced the percentage of viable cells (around 20\%) and increased the percentage of Annexin V/PI-positive cells compared with control cells $(1,2 \%$ versus 9,0\%), in both tumor cell lines (Fig. 5A and Fig. 5B). These results suggest that HHTP induces cell death by apoptotic mechanisms.

In an additional experiment, the cytotoxic differences between HHTP and its precursor HMTP were compared. The reduction of cytotoxicity of the non-phenol HMTP in comparison to HHTP was evident, since glioma cells treated with $5 \mu \mathrm{mol} \mathrm{L}{ }^{-1}$ HMTP for 48 h showed no significant difference in cell viability compared to the control (Fig. SI08a). However, viability was affected at higher concentrations of HMTP, reaching 35\% reduction at the highest concentration of HMTP $\left(25 \mu \mathrm{mol} \mathrm{L}{ }^{-1}\right)$ (Fig. SI08a). Also, the proportion of sub-G1 hypodiploid cells after HMTP treatment was slightly increased (around 3.7\%), only at the highest concentration of HMTP used (Fig. SI08b). 
Our results revealed that HHTP has a similar effect to other polyphenolic compounds, such as curcumin, apigenin, genistein, (-)epigallocatechin and (-)epigallocatechin-3-gallate, which can induce cell death by apoptosis in glioma and lungtumor cells and can increase the anti-neoplastic activity of chemotherapeutic drugs. (Zanotto-Filho et al. 2015; Das et al. 2010; De Oliveira et al. 2010; Lu et al. 2011) Cell surface exposure of phosphatidylserine is a feature of cells dying through the process of apoptosis, so it is interesting to analyze the time taken for the observed phosphatidylserine translocation induced by HHTP in comparison to other polyphenolic compounds. Here, we showed that HHTP induces increase in the percentage of Annexin V-positive cells (proportion of approximately 9\%) in both glioma cells (U87MG and T98G) after 48h of treatment. Zanotto and co-workers showed no significant differences in the Annexin Vpositive cell population in U251MG glioma cells after treatment with curcumin for the same period of time (48h), however treatment with curcumin for $120 \mathrm{~h}$ promotes an increase (approximately $12 \%$ ) of Annexin V-stained cells. (Zanotto-Filho et al. 2015) In another study, El Bachá and co-workers observed the treatment of glioblastoma GL-15 cells with catechol (1,2 dihydroxybenzene) for $48 \mathrm{~h}$ leads to increase in the percentage of cells labeled with annexin in around $20 \%$ (De Oliveira et al. 2010), but at catechol concentration 60 times higher than we used here for HHTP compound (600 $\mu \mathrm{M}$ versus $10 \mu \mathrm{M})$. In addition, we observed a relationship between cytotoxic activity and the HHTP properties, especially with respect to the ability of the polyphenol and conjugated aromatic rings to stabilize the oxidized radical form, demonstrating a potential adjuvant use of HHTP for chemotherapy.

\section{Conclusions}


HHTP exhibited mainly the catechol redox properties, with accessible higher oxidation states, but improved by the presence of fused aromatic rings. In solution, the free HHTP reached the tris-semiquinone monoradical state, as demonstrated by UV-vis spectroelectrochemistry. The chemically oxidized or aged samples of HHTP exhibited a typical radical EPR signal. The radical form of HHTP is probably responsible for its high cytotoxicity. Different tumor cell lines, including glioma and lung cells, lost their viability after treatment with HHTP, showing increases in the percentages of hypodiploid and Annexin V/PI-positive cells. The results revealed that free HHTP has an intrinsic cytotoxic effect on human tumor cell lines, and although the detailed mechanisms underlying the cytotoxic effects of HHTP on tumor cells warrant further research, the present results suggest that HHTP may induce cell death, probably by apoptotic pathways.

Acknowledgments

The authors thank the following institutions for financial support: Conselho Nacional de Desenvolvimento Científico e Tecnológico (CNPq/INCT) and Fundação Araucária.

\section{References}

Adamson, J., Funnell, N. P., Thompson, A. L. and Goodwin, A. L. 2014. Structural investigation of a hydrogen bond order-disorder transition in a polar one-dimensional confined ice. PCCP Phys. Chem. Chem. Phys., 16(6): 2654-2659. doi:10.1039/c3cp53994f 
Balasubramanian, K., Mirnikjoo, B., Schroit, A. J. 2007. Regulated externalization of phosphatidylserine at the cell surface: implications for apoptosis. J. Biol. Chem. 282(25): 1835718364. doi: 10.1074/jbc.M700202200

Barthram, A. M., Cleary, R. L., Kowallick, R. and Ward, M. D. 1998. A new redox-tunable near-IR dye based on a trinuclear ruthenium(II) complex of hexahydroxytriphenylene. Chem. Commun., (24): 2695-2696. doi:10.1039/a807835a

Barthram, A. M., Reeves, Z. R., Jeffery, J. C. and Ward, M. D. 2000. Polynuclear osmiumdioxolene complexes: comparison of electrochemical and spectroelectrochemical properties with those of their ruthenium analogues. Dalton Trans., (18): 3162-3169. doi:10.1039/b004858p

Beattie, D. R., Hindmarsh, P., Goodby, J. W., Haslam, S. D. and Richardson, R. M. 1992. Triphenylene hexa-n-alkylcyclohexanoates: a new series of disc-like liquid crystals. J. Mater. Chem., 2(12): 1261-1266. doi:10.1039/jm9920201261

Brandes, A. A., Basso, U., Reni, M., Vastola, F., Tosoni, A., Cavallo, G., Scopece, L., Ferreri, A. J., Panucci, M. G., Monfardini, S. and Ermani, M. 2004. First-line chemotherapy with cisplatin plus fractionated temozolomide in recurrent glioblastoma multiforme: A phase II study of the Gruppo Italiano Cooperativo di Neuro-Oncologia. J. Clin. Oncol., 22(9): 1598-1604. doi:10.1200/jco.2004.11.019 
Côté, A. P., Benin, A. I., Ockwig, N. W., O'Keeffe, M., Matzger, A. J. and Yaghi, O. M. 2005. Porous, crystalline, covalent organic frameworks. Science, 310(5751): 1166-1170. doi:10.1126/science.1120411

Das, A., Banik, N. L. and Ray, S. K. 2010. Flavonoids activated caspases for apoptosis in human glioblastoma T98G and U87MG cells but not in human normal astrocytes. Cancer, 116(1): 164-176. doi:10.1002/cncr.24699

De Cathelineau, A. M. and Henson, P. M. 2003. The final step in programmed cell death: phagocytes carry apoptotic cells to the grave. Essays Biochem. 39: 105-117. doi: $10.1042 / \mathrm{bse} 0390105$

De Oliveira, D. M., Pitanga, B. P. S., Grangeiro, M. S., Lima, R. M. F., Costa, M. F. D., Costa, S. L., Clarencio, J. and El-Bacha, R. S. 2010. Catechol cytotoxicity in vitro: Induction of glioblastoma cell death by apoptosis. Hum. Exp. Toxicol., 29(3): 199-212. doi:10.1177/0960327109360364

Giovanelli, L., Ourdjini, O., Abel, M., Pawlak, R., Fujii, J., Porte, L., Themlin, J.-M. and Clair, S. 2014. Combined Photoemission Spectroscopy and Scanning Tunneling Microscopy Study of the Sequential Dehydrogenation of Hexahydroxytriphenylene on $\operatorname{Ag}(111)$. J. Phys. Chem. C, 118(27): 14899-14904. doi:10.1021/jp501849h

Grange, C. S., Meijer, A. J. H. M. and Ward, M. D. 2010. Trinuclear ruthenium dioxolene complexes based on the bridging ligand hexahydroxytriphenylene: electrochemistry, spectroscopy, and near-infrared electrochromic behaviour associated with a reversible seven-membered redox chain. Dalton Trans., 39(1): 200-211. doi:10.1039/b918086a 
Guo, J.-H., Zhang, H., Tang, Y. and Cheng, X. 2013. Hydrogen spillover mechanism on covalent organic frameworks as investigated by ab initio density functional calculation. PCCP Phys. Chem. Chem. Phys., 15(8): 2873-2881. doi:10.1039/c2cp44007e

Henderson, P., Beyer, D., Jonas, U., Karthaus, O., Ringsdorf, H., Heiney, P. A., Maliszewskyj, N. C., Ghosh, S. S., Mindyuk, O. Y. and Josefowicz, J. Y. 1997. Complex ordering in thin films of diand trifunctionalized hexaalkoxytriphenylene derivatives. J. Am. Chem. Soc., 119(20): 4740-4748. doi:10.1021/ja964036w

Hmadeh, M., Lu, Z., Liu, Z., Gandara, F., Furukawa, H., Wan, S., Augustyn, V., Chang, R., Liao, L., Zhou, F., Perre, E., Ozolins, V., Suenaga, K., Duan, X. F., Dunn, B., Yamamoto, Y., Terasaki, O. and Yaghi, O. M. 2012. New Porous Crystals of Extended Metal-Catecholates. Chem. Mat., 24(18): 3511-3513. doi:10.1021/cm301194a

Karthaus, O., Ringsdorf, H., Tsukruk, V. V. and Wendorff, J. H. 1992. Columnar ordering of liquidcrystalline discotics in Langmuir-Blodgett-films. Langmuir, 8(9): 2279-2283. doi:10.1021/la00045a034

Kocyigit, O., Kursunlu, A. N. and Guler, E. 2010. Complexation properties and synthesis of a novel Schiff base with triphenylene nucleus. J. Hazard. Mater., 183(1-3): 334-340. doi:10.1016/j.jhazmat.2010.07.029

Kueng, W., Silber, E. and Eppenberger, U. 1989. Quantification of cells cultured on 96-well plates. Anal. Biochem., 182(1): 16-19. doi:10.1016/0003-2697(89)90710-0 
Kumar, S. 2004. Recent developments in the chemistry of triphenylene-based discotic liquid crystals. Liq. Cryst., 31(8): 1037-1059. doi:10.1080/02678290410001724746

Leventis, P. A. and Grinstein, S. 2010. The distribution and function of phosphatidylserine in cellular membranes. Annu. Rev. Biophys. 39: 407-427. doi: 10.1146/annurev.biophys.093008.131234

Liu, X.-Y., He, J., Yu, J.-X., Li, Z.-X. and Fan, Z.-Q. 2014. Theoretical study of molecular hydrogen and spiltover hydrogen storage on two-dimensional covalent-organic frameworks. Chinese Phys. B, 23(6): 067303. doi:10.1088/1674-1056/23/6/067303

Lu, H.-F., Chie, Y.-J., Yang, M.-S., Lu, K.-W., Fu, J.-J., Yang, J.-S., Chen, H.-Y., Hsia, T.-C., Ma, C.-Y., Ip, S.-W. and Chung, J.-G. 2011. Apigenin induces apoptosis in human lung cancer H460 cells through caspase- and mitochondria-dependent pathways. Hum. Exp. Toxicol., 30(8): 10531061. doi:10.1177/0960327110386258

Manickam, M., Belloni, M., Kumar, S., Varshney, S. K., Rao, D. S. S., Ashton, P. R., Preece, J. A. and Spencer, N. 2001. The first hexagonal columnar discotic liquid crystalline carbazole derivatives induced by noncovalent pi-pi interactions. J. Mater. Chem., 11(11): 2790-2800. doi:10.1039/b103052n

Medina, D. D., Werner, V., Auras, F., Tautz, R., Dogru, M., Schuster, J., Linke, S., Doeblinger, M., Feldmann, J., Knochel, P. and Bein, T. 2014. Oriented thin films of a benzodithiophene covalent organic framework. ACS Nano, 8(4): 4042-4052. doi:10.1021/nn5000223 
Ogoshi, T., Hiramitsu, S., Yamagishi, T.-A. and Nakamoto, Y. 2009. Columnar stacks of star- and tadpole-shaped polyoxazolines having triphenylene moiety and their applications for synthesis of wire-assembled gold nanoparticles. Macromolecules, 42(8): 3042-3047. doi:10.1021/ma900169j

Riccardi, C. and Nicoletti, I. 2006. Analysis of apoptosis by propidium iodide staining and flow cytometry. Nature Protoc., 1(3): 1458-1461. doi:10.1038/nprot.2006.238

Schweigert, N., Zehnder, A. J. B. and Eggen, R. I. L. 2001. Chemical properties of catechols and their molecular modes of toxic action in cells, from microorganisms to mammals. Environ. Microbiol., 3(2): 81-91. doi:10.1046/j.1462-2920.2001.00176.x

Segawa, K., Kurata, S., Yanagihashi, Y., Brummelkamp, T. R., Matsuda, F., Nagata, S. 2014. Caspase-mediated cleavage of phospholipid flippase for apoptotic phosphatidylserine exposure. Science 344(6188): 1164-1168. doi: 10.1126/science.1252809

Segawa, K. and Nagata, S. 2015. An Apoptotic 'Eat Me' Signal: Phosphatidylserine Exposure. Trends Cell Biol. 25(11): 639-650. doi: 10.1016/j.tcb.2015.08.003

Silvani, A., Eoli, M., Salmaggi, A., Lamperti, E., Maccagnano, E., Broggi, G. and Boiardi, A. 2004. Phase II trial of cisplatin plus temozolomide, in recurrent and progressive malignant glioma patients. J. Neuro-Oncol., 66(1-2): 203-208. doi:10.1023/b:neon.0000013479.64348.69 
Suzuki, J., Denning, D. P., Imanishi, E., Horvitz, H. R., Nagata, S. 2013. Xk-related protein 8 and CED-8 promote phosphatidylserine exposure in apoptotic cells. Science. 341(6144): 403-406. doi: $10.1126 /$ science. 1236758

Tsukruk, V. V., Wendorff, J. H., Karthaus, O. and Ringsdorf, H. 1993. Packing of columns in Langmuir-Blodgett-films of discotic mixtures with charge-transfer interactions. Langmuir, 9(2): 614-618. doi:10.1021/la00026a042

Vaes, A., Van der Auweraer, M., De Schryver, F. C., Laguitton, B., Jonas, A., Henderson, P. and Ringsdorf, H. 1998. Y-type Langmuir-Blodgett films of 2,3-bis((2-hydroxyethyl)oxy)-6,7,10,11tetrakis(pentyloxy)triphenylene: An X-ray reflection study. Langmuir, 14(18): 5250-5254. doi:10.1021/la971253h

Xiang, Z., Cao, D., Lan, J., Wang, W. and Broom, D. P. 2010. Multiscale simulation and modelling of adsorptive processes for energy gas storage and carbon dioxide capture in porous coordination frameworks. Energ. Environ. Sci., 3(10): 1469-1487. doi:10.1039/c0ee00049c

Yuan, Y., Ren, H., Sun, F., Jing, X., Cai, K., Zhao, X., Wang, Y., Wei, Y. and Zhu, G. 2012. Targeted Synthesis of a 3D Crystalline Porous Aromatic Framework with Luminescence Quenching Ability for Hazardous and Explosive Molecules. J. Phys. Chem. C, 116(50): 26431-26435. doi:10.1021/jp309068x

Zanotto-Filho, A., Braganhol, E., Klafke, K., Figueiró, F., Terra, S.R., Paludo, F.J., Morrone, M., Bristot, I.J., Battastini, A.M., Forcelini, C.M., Bishop, A.J., Gelain, D.P., Moreira, J.C. 2015. 
Autophagy inhibition improves the efficacy of curcumin/temozolomide combination therapy in glioblastomas. Cancer Lett. 358(2): 220-231. doi: 10.1016/j.canlet.2014.12.044

Zustovich, F., Lombardi, G., Della Puppa, A., Rotilio, A., Scienza, R. and Pastorelli, D. 2009. A Phase II Study of Cisplatin and Temozolomide in Heavily Pre-treated Patients with Temozolomiderefractory High-grade Malignant Glioma. Anticancer Res., 29(10): 4275-4279. 
Figure captions

Fig. 1. (A) Cyclic voltammogram of HHTP at $20 \mathrm{mV} \mathrm{s}^{-1}$. (B) Squarewave voltammogram in -1.5 to $1.0 \mathrm{~V}$ direction and reverse. (C) UV-vis spectroelectrochemical evolution of HHTP solution while a $1.0 \mathrm{~V}$ potential was applied. (D) EPR spectrum of aged HHTP sample at $77 \mathrm{~K}$. Inset: Structure of the tris-semiquinone form of HHTP. * corresponds to the internal standard chromium-doped magnesium oxide signal.

Fig. 2. Effects of HHTP on cell viability and morphology. (A) Viability of the tumor cell lines after HHTP treatment. Values represent the mean \pm SD of the percentage of viable cells compared to the control (data represent three independent experiments, each in triplicate). Significant differences were found in the percentage of viable cells at all HHTP concentrations tested $(*=\mathrm{p}<0.05 ; * *=\mathrm{p}<0.01 ; * * *=\mathrm{p}<0.001)$. (B) Morphological assessment of U87MG cells after treatment with HHTP for $48 \mathrm{~h}$. Optical microscopy analysis (x230). (Panel A) Control - DMSO vehicle; (Panel B) HHTP $=5 \mu \mathrm{mol} \mathrm{L}^{-1}$; (Panel C) $\mathrm{HHTP}=10 \mu \mathrm{mol} \mathrm{L}{ }^{-1}$; (Panel D) HHTP $=25 \mu \mathrm{mol} \mathrm{L}^{-1}$.

Fig. 3. Effects of HHTP and cisplatin on cell viability. Viability of the glioma cell lines after HHTP treatment in comparison to cisplatin treatment. HHTP and cisplatin were used at different concentrations ( 5 to $25 \mu \mathrm{mol} \mathrm{L}{ }^{-1}$ ) for $48 \mathrm{~h}$. (A) U87MG cells; (B) T98G cells; (C) A172 cells. Values represent the mean \pm SD of the percentage of viable cells compared 
to the controls (data represent three independent experiments, each in triplicate, $* * *=$ $\mathrm{p}<0.001)$.

Fig. 4. Effects of HHTP on DNA fragmentation. Fragmented DNA content of glioma cells treated with HHTP $\left(10 \mu \mathrm{mol} \mathrm{L} \mathrm{L}^{-1}\right.$ for $\left.48 \mathrm{~h}\right)$. Data represent three independent experiments, each in triplicate $(* * *=\mathrm{p}<0.001)$.

Fig. 5. Apoptosis experiment using Annexin-V/PI double-staining method by flow cytometer. Human glioma cells were treated with HHTP $\left(10 \mu \mathrm{mol} \mathrm{L}{ }^{-1}\right)$ or DMSO (vehiclecontrol group) for $48 \mathrm{~h}$. After that, cells were processed in $\mathrm{Ca}^{2+}$ rich buffer with FITC conjugated annexin- $\mathrm{V}$ and propidium iodide, and samples were analyzed by flow cytometer. (A-D) Representative scatter plots of PI (y-axis) vs Annexin V (x-axis) in HHTP-treated glioma cells. Viable cells are shown in the lower left quadrant, Annexin Vpositive cells are shown in the lower right quadrant, Annexin V/PI-positive cells are shown in the upper right quadrant, and PI-positive cells are shown in the upper left quadrant. (A) Control U87MG cells, (B) U87MG treated with HHTP (C) Control T98G cells (D) T98G treated with HHTP (E) Quantification of apoptotic U87MG cells. (F) Quantification of apoptotic T98G cells; Data represent three independent experiments, each in triplicate $(* *=$ $\mathrm{p}<0.01 ; * * *=\mathrm{p}<0.001)$. 

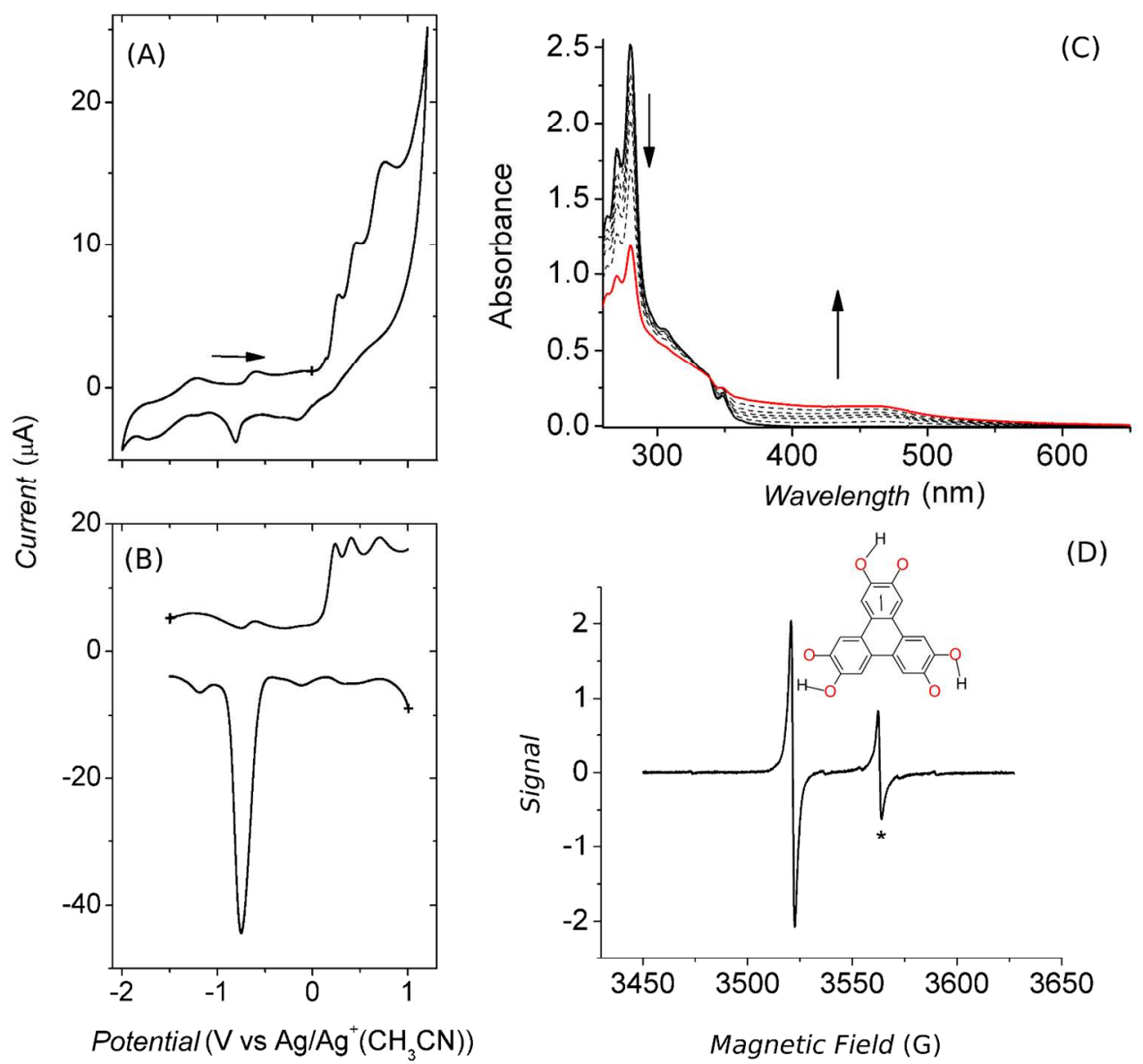

Fig. 1(A) Cyclic voltammogram of HHTP at $20 \mathrm{mV} \mathrm{s}^{-1}$. (B) Square wave voltammogram in -1.5 to $1.0 \mathrm{~V}$ direction and reverse. (C) UV-vis spectroelectrochemical evolution of HHTP solution while a $1.0 \mathrm{~V}$ potential was applied. (D) EPR spectrum of aged HHTP sample at $77 \mathrm{~K}$. Inset: Structure of the tris-semiquinone form of HHTP. * corresponds to the internal standard chromium-doped magnesium oxide signal. $135 \times 124 \mathrm{~mm}(300 \times 300 \mathrm{DPI})$ 
(A)

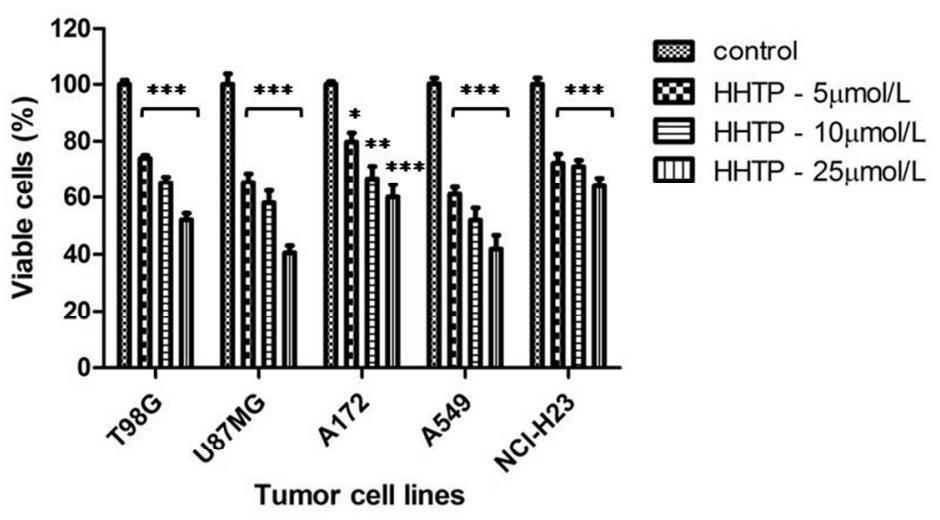

(B)
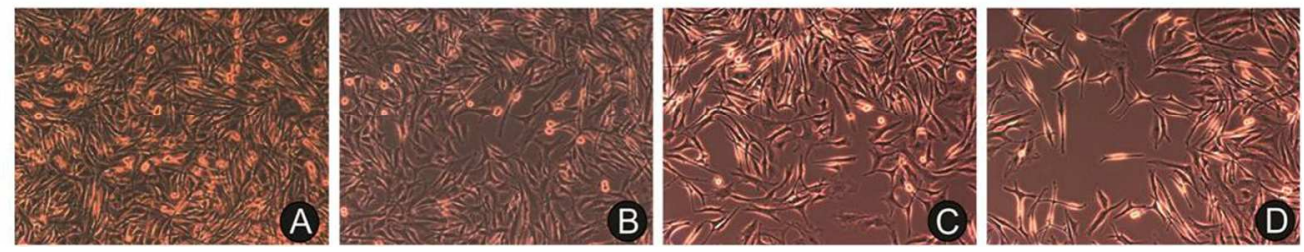

Fig. 2. Effects of HHTP on cell viability and morphology. (A) Viability of the tumor cell lines after HHTP treatment. Values represent the mean \pm SD of the percentage of viable cells compared to the control (data represent three independent experiments, each in triplicate). Significant differences were found in the percentage of viable cells at all HHTP concentrations tested $(*=p<0.05 ; * *=p<0.01 ; * * *=p<0.001)$.

(B) Morphological assessment of U87MG cells after treatment with HHTP for $48 \mathrm{~h}$. Optical microscopy analysis (x230). (Panel A) Control - DMSO vehicle; (Panel B) HHTP $=5 \mu \mathrm{mol} \mathrm{L}^{-1}$; (Panel C) HHTP $=10 \mu \mathrm{mol}$ L-1; (Panel D) HHTP $=25 \mu \mathrm{mol} \mathrm{L}{ }^{-1}$. $96 \times 68 \mathrm{~mm}(300 \times 300 \mathrm{DPI})$ 

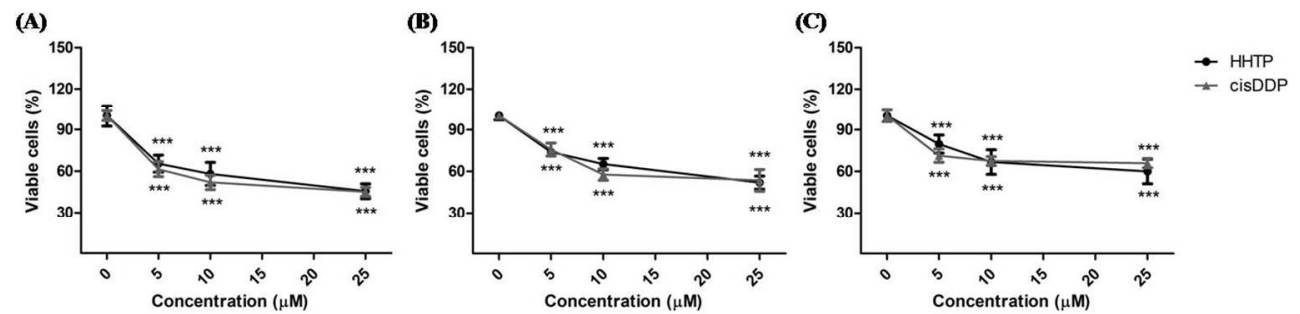

Fig. 3. Effects of HHTP and cisplatin on cell viability. Viability of the glioma cell lines after HHTP treatment in comparison to cisplatin treatment. HHTP and cisplatin were used at different concentrations (5 to $25 \mu \mathrm{mol} \mathrm{L}^{-}$

${ }^{1}$ ) for $48 \mathrm{~h}$. (A) U87MG cells; (B) T98G cells; (C) A172 cells. Values represent the mean \pm SD of the percentage of viable cells compared to the controls (data represent three independent experiments, each in triplicate, $* * *=p<0.001)$.

$122 \times 31 \mathrm{~mm}(300 \times 300 \mathrm{DPI})$ 


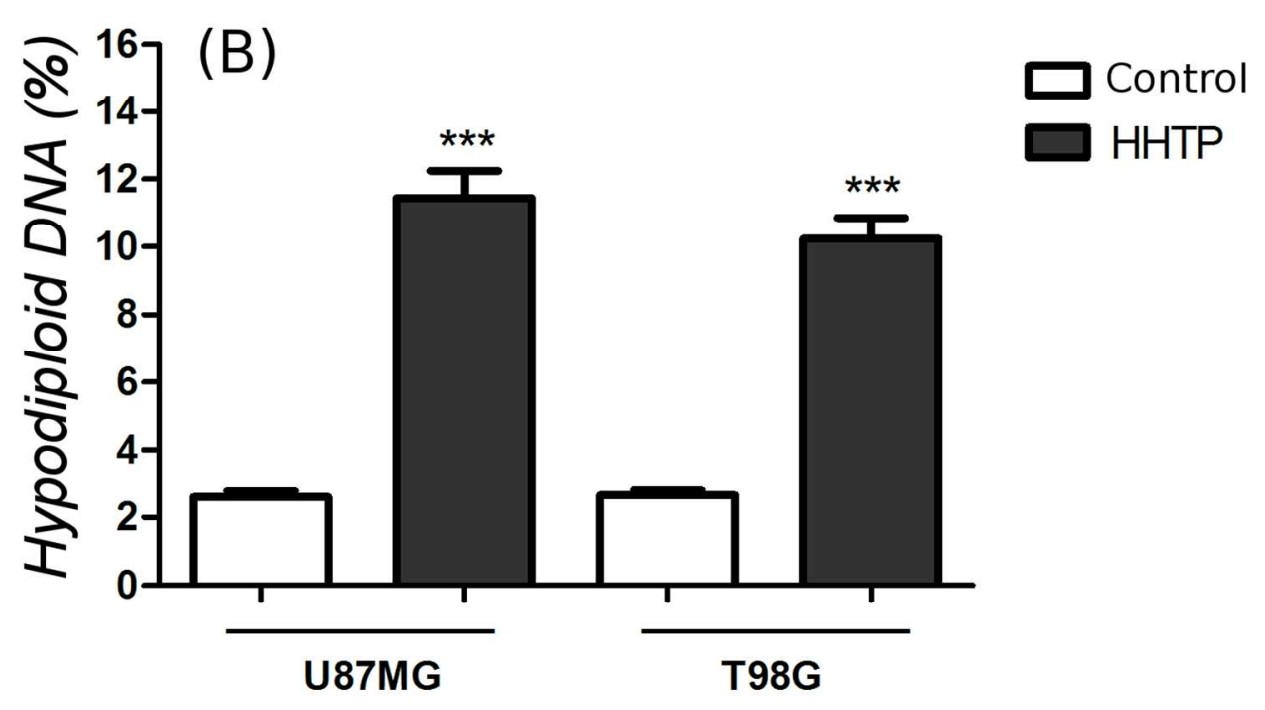

Fig. 4. Effects of HHTP on DNA Fragmentation. Fragmented DNA content of glioma cells treated with HHTP $\left(10 \mu \mathrm{mol} \mathrm{L}{ }^{-1}\right.$ for $\left.48 \mathrm{~h}\right)$. The data represent three independent experiments, each in triplicate $(* * *=$ $\mathrm{p}<0.001)$.

$121 \times 70 \mathrm{~mm}(300 \times 300 \mathrm{DPI})$ 

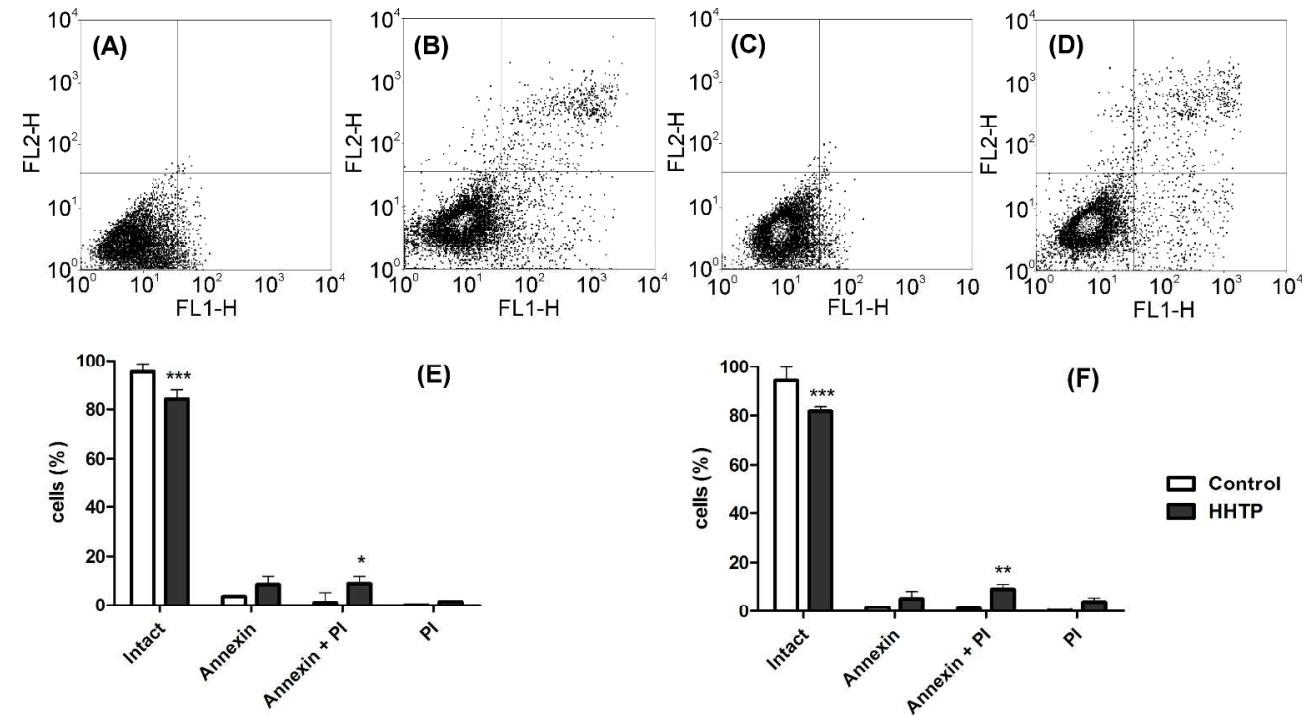

Fig. 5. Apoptosis experiment using Annexin-V/PI double-staining method by flow cytometer. Human glioma cells were treated with HHTP $\left(10 \mu \mathrm{mol} \mathrm{L}^{-1}\right)$ or DMSO (vehicle-control group) for $48 \mathrm{~h}$. After that, cells were processed in $\mathrm{Ca}^{2+}$ rich buffer with FITC conjugated annexin- $\mathrm{V}$ and propidium iodide, and samples were analyzed by flow cytometer. (A-D) Representative scatter plots of PI (y-axis) vs Annexin V (x-axis) in HHTPtreated glioma cells. Viable cells are shown in the lower left quadrant, Annexin $V$-positive cells are shown in the lower right quadrant, Annexin V/PI-positive cells are shown in the upper right quadrant, and PI-positive cells are shown in the upper left quadrant. (A) Control U87MG cells, (B) U87MG treated with HHTP (C)

Control T98G cells (D) T98G treated with HHTP (E) Quantification of apoptotic U87MG cells. (F) Quantification of apoptotic T98G cells; Data represent three independent experiments, each in triplicate (** $=\mathrm{p}<0.01 ; * * *=\mathrm{p}<0.001)$
$270 \times 149 \mathrm{~mm}(300 \times 300 \mathrm{DPI})$ 